\title{
A GOVERNANÇA CORPORATIVA COMO UM DIFERENCIAL PARA O VALOR DE MERCADO DAS EMPRESAS LISTADAS NA BM\&FBOVESPA NO ANO DE 2012 $^{1}$
}

\author{
THE CORPORATE GOVERNANCE AS A DIFFERENTIAL FOR THE MARKET \\ VALUE OF COMPANIES LISTED ON THE BM\&FBOVESPA IN YEAR 2012
}

\section{EL GOBIERNO CORPORATIVO COMO UN DIFERENCIAL PARA EL VALOR DE MERCADO DE LAS EMPRESAS QUE COTIZAN EN LA BM\&FBOVESPA EN EL AÑO 2012}

Marina Bezerra da Silva, Bacharel em Administração de Empresas pela Universidade Federal do Piauí (UFPI). Endereço Profissional: Instituto Federal do Piauí, Instituto Federal do Piauí - Campus Oeiras, Rua Projetada, S/N, Uberaba II, Oeiras, PI, CEP: 64500000. Telefone: (089) 99225349. URL da Homepage: www.ifpi.edu.br. E-mail: meurymarina@hotmail.com

Samuel Façanha Câmara, Pós Doutorado em Gestão da Inovação na FGV-EBAPE. Endereço Profissional: Universidade Estadual do Ceará, Centro de Estudos Sociais Aplicados, Mestrado Em Administração, Av. Paranjana, nº 1700, Campus do Itaperi, Bloco CESA, Coordenação do Mestrado Acadêmico em Administração, Itaperi, Fortaleza, CE, CEP: 60740000. Telefone: (85) 31019940/ Fax: (85) 31019940. URL da Homepage: http://www.uece.br. E-mail: sfcamara@ig.com.br.

\section{RESUMO}

A governança corporativa, mecanismo que fomenta e reforça a transparência e a ética na gestão das organizações, vem sendo alvo de bastantes estudos, ultimamente. Isso vem se dando, principalmente, devido às descobertas recentes de grandes fraudes na gestão das corporações. Mecanismos de controle vêm tentando reduzir tais problemáticas, como, por exemplo, os níveis de governança corporativa diferenciados da BM\&FBOVESPA. Esta pesquisa objetivou verificar se houve influência dos níveis diferenciados de governança corporativa das companhias listadas na BM\&FBOVESPA sobre o valor de mercado das mesmas, no ano de 2012. Para isto, através do Método de Máxima Verossimilhança (MVS), foi utilizada uma regressão linear simples entre nível de governança corporativa e valor de mercado. Verificou-se que os níveis de governança corporativa influenciam o desempenho de mercado (valor de mercado) das organizações analisadas, devendo a governança corporativa ser incentivada no âmbito da gestão corporativa.

Palavras-chave: Governança corporativa; Transparência; Desempenho; Mercado de capitais.

\footnotetext{
Artigo publicado anteriormente nos Anais do II Encontro de Administração de Floriano (ENAF).

${ }^{1}$ Artigo submetido em 18/12/2014, revisado em 13/02/2015, aceito em 26/02/2015 e divulgado em 30/06/2015 pelo Editor João Carlos Hipólito Bernardes do Nascimento, após double blind review.
}

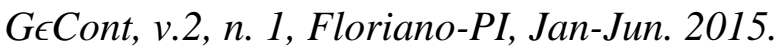




\section{ABSTRACT}

Corporate governance, which is a mechanism that encourages and strengthens transparency and ethics in the management of organizations, has been the subject of many studies lately. This has come about, mainly, due to recent discoveries of large-scale fraud in the management of corporations. Control mechanisms has been trying to reduce such problems, such as, for example, the differentiated levels of corporate governance of BM\&FBOVESPA. This research aimed to verify if there was no influence of differentiated levels of corporate governance of listed companies at the BM\&FBOVESPA on the market value of the same, in the year 2012. To do this, using the Method of Maximum Likelihood (MVS), was used a simple linear regression between the level of corporate governance and market value. It was found that the levels of corporate governance influence the performance of the market (market value) of organizations surveyed, and the corporate governance be encouraged in the context of corporate governance.

Keywords: Corporate governance; Transparency; Performance; Capital market.

\section{RESUMEN}

Gobierno corporativo, que es un mecanismo que alienta y fortalece la transparencia y la ética en la gestión de las organizaciones, ha sido objeto de numerosos estudios en los últimos meses. Esto ha sido, principalmente, debido a los recientes descubrimientos de un fraude a gran escala en la gestión de las sociedades. Mecanismos de control ha estado tratando de reducir estos problemas, como, por ejemplo, los niveles de gobierno corporativo diferenciado $B M \& F B O V E S P A$. Esta investigación tuvo como objetivo comprobar si no hay influencia de niveles diferenciados de gobierno corporativo de las sociedades cotizadas en la BM\&FBOVESPA en el valor de mercado de la misma, en el año 2012. Para ello, utilizando el Método de Máxima Verosimilitud (MVS), se utilizó la regresión lineal simple entre el nivel de la gestión empresarial y el valor de mercado. Se constató que los niveles de gobierno de las empresas influyen en el rendimiento del mercado (valor de mercado) de las organizaciones encuestadas, y el gobierno corporativo en el contexto de la gestión empresarial.

Palabras-clave: Gobierno corporativo; Transparencia; Rendimiento; Mercado de capitales.

\section{INTRODUÇÃO}

\footnotetext{
tualmente vem aumentando a quantidade de empresas brasileiras de capital aberto, o que se dá devido às grandes oportunidades financeiras que surgem quando tais organizações se lançam nos mercados de capitais.
}

A gestão destas empresas é composta por conselhos de administração, pela diretoria da empresa e pelos acionistas. Camilo, Marcon e Bandeira-de-Mello (2011) explicam que os acionistas elegem e controlam os membros do conselho, enquanto estes elegem e controlam os diretores executivos. Entretanto, nem sempre os interesses de gestores e executivos estão alinhados aos interesses dos acionistas e investidores das companhias, o que gera conflitos de confiança e de interesses entre stakeholders (partes interessadas) e dirigentes organizacionais.

Esse dissenso se refere a um paradigma pelo qual as companhias de capital aberto sempre passaram, devido a sua estrutura de gestão ser separada da estrutura de propriedade. Isso geralmente provoca certos impasses entre os reais interesses dos gestores e os dos acionistas da organização.

GєCont, v.2, n. 1, Floriano-PI, Jan-Jun. 2015. 
A governança corporativa surge, assim, como um mecanismo que busca reduzir esse conflito, através da transparência nas ações dos gestores e do conselho de administração das organizações (ALVES, 2001). Tal estrutura faz com que haja maior alinhamento dos interesses dos gestores aos dos acionistas, e a confiança destes na organização, tendendo a aumentar o valor das mesmas (SILVEIRA, 2010).

O presente trabalho tem como objetivo principal verificar se houve influência dos níveis diferenciados de governança corporativa das companhias listadas na BM\&FBOVESPA sobre o valor de mercado no ano de 2012.

Como objetivos específicos, buscou-se analisar a importância da governança corporativa para o desempenho de mercado e verificar a variação no desempenho de mercado ao ocorrer variações nos níveis de governança corporativa da BM\&FBOVESPA.

A pesquisa tem a aplicação teórica de contribuir com os estudos sobre governança e finanças corporativas, a partir da análise do valor de mercado e do desempenho financeiro das organizações. Relativo à aplicação prática, o estudo auxilia tanto aos investidores e demais stakeholders, como àqueles que pretendem entrar nesse mercado. Outra aplicação é a de servir como instrumento para diretores e conselhos de administração analisarem as estruturas de gestão no que se refere às boas práticas de governança em suas empresas, avaliando se é ou não compensatória a gestão corporativa com a governança.

Apesar do trabalho se voltar, principalmente, para as corporações de capital aberto, enfatiza-se ainda a importância de tais estudos também para as pequenas e microempresas que não sejam listadas na Bolsa e que não possuam capital aberto, dado que todos os tipos de empresas possuem stakeholders.

Pesquisas desta natureza têm caráter macroeconômico, sendo importantes, também, para instituições e órgãos que regem a atividade empresarial, inclusive os mercados de capitais, que buscam o crescimento e o desenvolvimento saudável da economia. Tal importância se comprova, principalmente, quando são verificadas as grandes destruições causadas quando problemas de agência são descobertos, podendo, de acordo com as dimensões adquiridas, alterar até mesmo a situação econômica dos países onde ocorrem.

Além desta introdução, o trabalho contém, na segunda seção, o referencial teórico, abordando os conceitos de governança corporativa e as teorias basilares sobre as quais a mesma se sustenta, além da revisão de literatura sobre a temática. Na terceira sessão, será descrita a metodologia utilizada. Na quarta seção, verificam-se os resultados obtidos, e em seguida, na quinta seção, encerra-se o estudo com as considerações finais acerca dos achados da pesquisa.

\section{REFERENCIAL TEÓRICO}

\subsection{Governança Corporativa}

Para o IBGC (2009), a governança corporativa é um sistema através do qual as organizações são dirigidas, monitoradas e incentivadas, o que é feito através de uma teia intangível de moral e ética, que relaciona gestores, colaboradores e demais stakeholders de uma empresa.

Neste sentido, o valor organizacional é o resultado da gestão dos diversos ativos tangíveis e intangíveis que a mesma possui. Domeneghetti e Meir (2009) consideram a governança corporativa como um ativo intangível que agrega valor à organização através da confiabilidade, segurança, credibilidade, transparência, marca e reputação. Estes fatores, 
segundo os autores, têm conquistado vários mercados, sendo cada vez mais enfatizados pelas Bolsas de Valores e mercados de capitais.

Barney e Hestery (2007) complementam essa abordagem enfatizando que a governança é um recurso valioso na medida em que é uma força organizacional intangível que permite à empresa obter uma oportunidade de mercado. Isso se gera a partir do aumento da confiança do investidor, dada a maior transparência com a qual a organização é gerida.

Ressalta-se que, para que o desempenho superior por meio da governança seja obtido, são necessários os princípios da transparência, equidade, prestação de contas e responsabilidade corporativa (IBGC, 2009).

De acordo com Marinelli (2005), a governança é um conceito relativo à forma como são exercidos o controle e a direção das organizações, permitindo aos acionistas um monitoramento estratégico e efetivo das mesmas no que tange ao acompanhamento das ações dos gestores e à regulação das relações entre os acionistas, conselhos de administração e o conselho fiscal, alinhando os objetivos dos diversos stakeholders. Neste sentido, ela objetiva aperfeiçoar o comportamento das pessoas e das instituições (ALVES, 2001).

Cova e Santos (2007) consideram que a ética e a moral devem embasar as decisões e as atitudes dos dirigentes, independentemente da legislação, o que provoca mudanças positivas nos resultados financeiros.

Assim, a adoção das práticas de governança corporativa pelas empresas de capital aberto vem promovendo grandes mudanças em suas formas de gestão, garantindo-se grandes transformações na forma como elas são percebidas pela comunidade investidora.

\subsection{Teoria do Agente-Principal e Conflitos de Agência}

Os problemas de agência se referem a conflitos de interesses, pois se de um lado os principais, que são os acionistas e investidores, devem ter seus interesses atendidos através da maximização de valor da empresa, do outro, os administradores e agentes nem sempre agem com uma conduta ética e moral na busca da maximização da riqueza dos acionistas (ROSS; WESTERFIELD; JAFFE, 2008; GITMAN, 2001).

Silveira, Barros e Famá (2003) afirmam que governança corporativa é o conjunto de mecanismos de incentivos e controles para redução dos problemas de agência. Importante se faz verificar que, com a redução destes conflitos, reduzem-se também os custos gerados por tais problemas (SAITO; SILVEIRA, 2008). Conforme Camilo, Marcon, Bandeira-de-Mello (2011), essa redução de custos se dá devido ao equilíbrio gerado nas relações e nos interesses dos acionistas, da firma e dos agentes. Tal equilíbrio é pautado pela ética.

Nesse aspecto, os acionistas das corporações apostam em governança, transparência e responsabilidade social corporativa. Vários mecanismos, inclusive legais, são criados para assegurar e proteger acionistas minoritários contra os problemas de agência. Mas, a gestão, através da governança, vai muito além das questões legais, tendo como objetivo essencial o aumento de valor das firmas (FERREIRA, 2004).

Rossetti e Andrade (2012) enfatizam que a governança corporativa tem suas raízes históricas baseadas na resolução dos conflitos de agência. Desta forma, é um modelo de gestão que reduz e elimina tais problemas, através da transparência e da ética, com o objetivo de aumentar o valor de uma organização.

A teoria da inexistência de contrato completo de Klein (1983 apud ROSSETTI; ANDRADE, 2012) afirma que vários desses desencontros de interesses podem existir devido à estrutura lacunosa dos contratos. Geralmente, esses contratos são incompletos devido à impossibilidade de se prever completamente a realidade. Essas "brechas" na legislação devem ser preenchidas pelas ações dos executivos da empresa. Não há, no entanto, uma forma legal que garanta completamente que esse controle residual de gestores (SILVEIRA, 2010) seja

GєCont, v.2, n. 1, Floriano-PI, Jan-Jun. 2015. 
realizado de forma ética, embasada nos objetivos dos acionistas e donos da empresa.

Já a teoria da inexistência de agente perfeito, prevista por Jensen e Meckling (1976 apud ROSSETTI; ANDRADE, 2012), propõe que os problemas de agência advenham da própria natureza do agente. Esta busca constantemente a maximização da sua utilidade, sobrepondo a sua preferência e os seus interesses pessoais acima dos objetivos dos demais interessados. Tais conflitos são problemas que surgem a partir da conduta moral e ética de gestores, podendo se transformar em grandes fraudes no cerne das corporações, bem como em crises financeiras no âmbito dos mercados de capitais.

Os problemas de agência fazem com que apareçam também os custos de agência. Rossetti e Andrade (2012) enfatizam que tais custos são gerados tanto a partir do oportunismo e das fraudes cometidas por gestores, ao se aproveitarem de seus cargos, quanto dos dispêndios realizados por acionistas, na tentativa de conciliar as intenções dos gestores às suas, através do alinhamento de interesses.

Citam-se como exemplos desses problemas os casos da Enron, nos Estados Unidos, da Parmalat, na Europa, ou do Banco Nacional, no Brasil. Tais casos gerados a partir de grandes fraudes contábeis, ao serem descobertos, geraram grandes perdas econômico-financeiras, provocando perdas irreparáveis aos seus acionistas.

Apesar de todos esses tipos de custos de agência existirem e provocarem grandes gastos nas empresas, as orientações acerca das boas práticas de governança corporativa, onde se inclui, por exemplo, o Código das Melhores Práticas de Governança Corporativa, do IBGC (2009), têm melhorado muita coisa em relação a tais problemas.

\subsection{Revisão de Literatura}

O estudo desenvolvido por Melo et al. (2013), através de Análise Multivariada da Variância (MANOVA), realizado com 72 empresas de quatro setores econômicos, listadas na BM\&FBOVESPA, verificou que a governança é um fator que valoriza ou desvaloriza as ações de uma firma, influenciando seu desempenho financeiro, de acordo com a confiança que os acionistas depositam na empresa. Corroboram com estes resultados, a pesquisa de Silveira, Barros e Famá (2006) realizada utilizando Mínimos Quadrados Ordinários (MQO), variáveis instrumentais e sistemas de equações simultâneas, e aplicada sobre 154 companhias abertas da BM\&FBOVESPA.

A prática da governança corporativa influencia também positivamente na qualidade das informações contábeis (GABRIEL; SILVEIRA, 2011). Somente a adesão aos níveis diferenciados da BM\&FBOVESPA, no entanto, não ocasiona retornos financeiros anormais e positivos, mas sim o anúncio do evento ao mercado (COLOMBO; GALI, 2010).

Cova e Santos (2007), de modo complementar aos estudos citados, concluem em suas pesquisas exploratórias sobre geração de valor, que os mecanismos de governança têm a possibilidade de influenciar o desenvolvimento de uma nação, através do aprimoramento do seu mercado de capitais.

Marinelli (2005) também conclui, através de estudo exploratório, que os mecanismos de governança vêm se fortalecendo, gerando vários benefícios à organização e a seus interessados. Tais benefícios se referem ao aumento do valor da ação das companhias, às maiores garantias oferecidas aos investidores, à maior flexibilidade, e à maior transparência. Estes fatores se referem a diferenciais objetivados pela generalidade dos investidores, sendo decisivos no momento do investimento.

A relação entre governança e desempenho é analisada também por Martins, Brito e Tescari (2013). Através de uma survey, em 117 díades de empresas fornecedoras de produtos químicos com atuação no Brasil, os autores verificam que a confiança, baseada em normas informais, é um mecanismo de controle que faz com que, a partir de relações colaborativas (laços baseados em confiança), sejam geradas rendas relacionais na empresa. Essas rendas 
geram e agregam valor à organização, influenciando direta e positivamente o seu desempenho.

Nas análises conduzidas por Marques (2011), em que se avaliaram a rentabilidade e a avaliação de mercado a partir da governança corporativa, para 117 empresas listadas na BM\&FBOVESPA, através de MQO e efeitos fixos, observou-se que somente a presença no Novo Mercado não gera ganhos na rentabilidade ou na avaliação de mercado. Ações ON e a presença de membros independentes no conselho trazem ganhos para a avaliação de mercado. Já a presença do executivo no conselho causa um efeito negativo na avaliação.

Rossoni e Machado-da-Silva (2013), ao analisarem 348 empresas, através de dados em painel, com base nos modelos de MQO, efeitos fixos e efeitos aleatórios, explicam que o desempenho organizacional não se condiciona somente aos elementos físicos e de gestão organizacional, mas aos componentes e fatores institucionais sociais e legítimos. A legitimidade, por sua vez, se refere à forma como a empresa se posiciona socialmente, diante de seus shareholders e stakeholders, estando eminentemente relacionada à governança.

Silveira (2004) estuda ainda a causalidade reversa. Através de regressão múltipla do tipo seção transversal, ele percebe que a estrutura de propriedade e as práticas de governança influenciam o desempenho da organização, da mesma forma que o desempenho da organização e a estrutura de propriedade e de gestão influenciam a qualidade da governança. Isso se deve ao fato de que quando a empresa se encontra com um bom desempenho, busca também melhorar seu relacionamento com investidores, através de transparência e ética.

\section{METODOLOGIA DA PESQUISA}

\subsection{Classificação da Pesquisa}

Quanto aos procedimentos técnicos e ao objeto, é classificada como um estudo de campo, pois foi realizada através da análise de todas as empresas listadas na BM\&FBOVESPA, no ano de 2012. Por estudar todas as empresas, tem-se também um censo.

Quanto à forma de abordagem ela é quantitativa. A pesquisa quantitativa tenta fazer uma demonstração do objeto pesquisado através da quantificação, ou seja, busca retratar numérica e logicamente uma determinada situação real que está sendo estudada. Assim, é possível se observar com maior grau de precisão e objetividade o objeto de estudo.

Classifica-se, em relação aos seus objetivos, como uma pesquisa explicativa ou causal, visto que tenta visualizar se há uma relação de causa e efeito entre as variáveis estudadas, nível de governança corporativa (Nível 1, Nível 2 e Novo Mercado) e o indicador de desempenho valor de mercado das empresas analisadas, ou seja, verificar se uma variável explica a outra.

\subsection{Coleta de Dados}

Este estudo foi realizado com todas as empresas listadas na BM\&FBOVESPA no ano de 2012. Foram escolhidos dados referentes a este ano devido à sua atualização na época em que se iniciou esta pesquisa.

A população total é de 226 (duzentos e vinte e seis) empresas, porém foram excluídas 54 (cinquenta e quatro), por apresentarem missings (dados faltosos) e 5 (cinco) por serem outliers, ficando 167 (cento e sessenta e sete) empresas para o estudo.

Os dados utilizados são secundários e foram provenientes através da base de 2012 da Economática ${ }^{\circledR}$, cedida pela Associação dos Profissionais de Investimento em Mercado de Capitais (APIMEC Nordeste). 


\subsection{Tratamento dos Dados}

Como o estudo se concentrou em uma relação causal entre a governança corporativa e o desempenho de mercado das empresas, foram trabalhadas análises de regressões.

Inicialmente, buscou-se compor um modelo de regressão linear múltipla, porém este não apresentou resultados significativos, mesmo após tentativas de transformação das variáveis. Assim, foi abandonado.

Desta forma, optou-se pela estimação de modelos de regressão linear simples, os quais apresentaram resultados significativos e relevantes. Foi utilizado o Método de Máxima Verossimilhança (MVS). Para Wooldridge (2007), este método, para modelos lineares clássicos, é igual ao método dos Mínimos Quadrados Ordinários (MQO), no entanto, considera e busca corrigir os problemas de heteroscedasticidade. O termo geral da regressão simples é dado pela seguinte equação (1).

$$
y=B_{0}+B_{1} x+u
$$

Para a composição das regressões, foi utilizado o software IBM SPSS Statistics 20, através do qual foram geradas e verificadas as características estatísticas e alguns gráficos referentes ao modelo estudado neste trabalho.

Para verificar a normalidade na distribuição residual foi utilizado o Teste Jarque-Bera (1981, apud GALDI; TEIXEIRA; LOPES, 2007)

Foram realizadas, ainda, através do Software R, as conversões de Box-Cox e YeoJohnson (2000, apud SOUZA et al., 2012), a fim de que o modelo estimado não apresentasse problema de heteroscedasticidade. Fávero et al. (2009) explicam que este problema é gerado devido à grande discrepância entre as escalas das variáveis utilizadas nas regressões, causando o problema da falta de normalidade na distribuição residual. Isso provoca grande dispersão entre os termos aleatórios (termos de erros) e a variável explicativa do modelo, perdendo-se a distribuição normal dos resíduos na curva de densidade da probabilidade normal.

Para Souza et al. (2012), os problemas de normalidade e heteroscedasticidade são corrigidos através de uma transformação Box-Cox. A partir dos dados a serem convertidos, é gerado um gráfico de verossimilhança que aponta um parâmetro $\lambda$ (lambda), sendo este o valor que maximiza a função log-verossimilhança perfilada, e devendo ser o critério de escolha da transformação de Box-Cox e Yeo-Johnson (2000, apud SOUZA et al., 2012), à qual as variáveis devem ser submetidas.

Este procedimento foi adotado nesta pesquisa, dado que as variáveis respostas, em sua forma primária, não apresentaram resíduos normalmente distribuídos.

\subsubsection{Variáveis dependentes e independentes}

Os dados relativos aos níveis de governança corporativa da BM\&FBOVESPA (Novo Mercado, Nível 2 e Nível 1) são as variáveis independentes do modelo estatístico utilizado na pesquisa, e foram coletados a partir da base de dados Economática ${ }^{\circledR}$. Os mesmos encontramse resumidos na Tabela 1 , junto à sua codificação e à quantidade de empresas que lhes compõem. 
Tabela 1 - Resumo dos níveis de governança corporativa da BM\&FBOVESPA (com outliers).

\begin{tabular}{c|c|c}
\hline Código & Governança & $\begin{array}{c}\text { Quantidade de } \\
\text { empresas }\end{array}$ \\
\hline 1 & Sem governança & 77 \\
2 & Nível 1 & 21 \\
3 & Nível 2 & 6 \\
4 & Novo Mercado & 68 \\
\hline
\end{tabular}

Fonte: Adaptado de Economática, 2013.

As variáveis dependentes, referentes ao valor de mercado das empresas listadas na BM\&FBOVESPA, no ano 2012, foram coletadas a partir da mesma base de dados.

Para o site institucional da Economática ${ }^{\circledR}$ (2014), o indicador valor de mercado se refere à multiplicação entre o valor de fechamento da ação e a quantidade de ações da companhia. De modo similar, Rogers, Securato e Ribeiro (2008) apontam o market value (valor de mercado) como a quantidade de ações por suas respectivas cotações, em uma determinada data.

As empresas pesquisadas encontram-se de forma resumida na Tabela 2.

Tabela 2 - Resumo das empresas listadas na BM\&FBOVESPA, em 2012, por setor de atuação (com outliers).

\begin{tabular}{c|c|c|c|c|c}
\hline Cód. & Setor & $\begin{array}{c}\text { Quant. de } \\
\text { Empresas }\end{array}$ & Cód. & Setor & $\begin{array}{c}\text { Quant. de } \\
\text { Empresas }\end{array}$ \\
\hline 1 & Alimentos e bebidas & 15 & 8 & Outros & 15 \\
2 & Construção & 20 & 9 & Papel e celulose & 5 \\
3 & Eletroeletrônicos & 6 & 10 & Petróleo e gás & 4 \\
4 & Energia elétrica & 34 & 11 & Química & 9 \\
5 & Máquinas industriais & 4 & 12 & Siderurgia \& Metalurgia & 16 \\
6 & Mineração & 5 & 13 & Têxtil & 20 \\
7 & Minerais não metálicos & 3 & 14 & Veículos e peças & 16 \\
\hline
\end{tabular}

Fonte: Adaptado de Economática, 2013.

\subsubsection{Modelo conceitual e matemático}

Neste estudo, foi estimado um modelo de regressão linear, representando a relação entre governança corporativa e valor de mercado empresas. O nível de governança corporativa é a variável independente, enquanto valor de mercado é a variável dependente.

O modelo estatístico e matemático da pesquisa foi composto de acordo com a regressão linear simples (2).

$$
\ln V M=B_{0}+B_{1} \cdot N i v G o v+u
$$

Conceitualmente, as variáveis se referem aos seguintes fatores:

ln VM- Logaritmo do valor de mercado da empresa. Representa a variável resposta e dependente do modelo expresso pela equação (2). A variação da mesma deve se dar em função das mudanças na variável explicativa. Ressalta-se que, para o valor de mercado da 
organização ser obtido, deve-se seguir à expressão $\mathrm{e}^{(\mathrm{y} \text { estimado) }}$, dada a conversão logarítmica (Box-Cox) realizada, buscando-se eliminar os problemas de heteroscedasticidade.

$B_{0}$ - Coeficiente linear da expressão. Representa o intercepto da reta de regressão, e expressa o valor da variável explicada ( $\ln \mathrm{VM})$, em condições de total ausência da variável explicativa (níveis de governança corporativa).

$B_{1}$ - Coeficiente angular da expressão. Este coeficiente determina a angulação ou inclinação da reta de regressão dos modelos. Representa o aumento ou redução da variável explicada, diante de alterações na variável explicativa.

NivGov - Nível de governança corporativa. Representa a variável explicativa e independente dos modelos de regressões. Neste estudo o NivGov varia de 0 a 3, conforme a Tabela 3, de acordo com a robustez que o nível da BM\&FBOVESPA que representa.

Tabela 3 - Níveis de governança corporativa e os valores considerados nos modelos estimados na pesquisa.

\begin{tabular}{c|c}
\hline Nível de Governança Corporativa & Valor \\
\hline Ausência de governança & 0 \\
Nível 1 & 1 \\
Nível 2 & 2 \\
Novo Mercado & 3 \\
\hline
\end{tabular}

Fonte: Dados da pesquisa, 2014.

$u$ - Termo de erro do modelo. Representa os valores residuais, que são as probabilidades estatísticas de ainda haver outras variáveis explicativas a serem inseridas no modelo.

\subsubsection{Hipóteses da pesquisa}

Para análise da relação entre nível de governança corporativa e valor de mercado das empresas listadas na BM\&FBOVESPA, no ano de 2012, foram lançadas duas hipóteses $\mathrm{H}_{1} \mathrm{e}$ $\mathrm{H}_{2}$, que estão descritas a seguir.

$\mathrm{H}_{1}-\mathrm{O}$ nível de governança corporativa não influencia o valor de mercado das empresas listadas na BM\&FBOVESPA.

$\mathrm{H}_{2}-\mathrm{O}$ nível de governança corporativa influencia o valor de mercado das empresas listadas na BM\&FBOVESPA.

A hipótese $\mathrm{H}_{1}$ será considerada a hipótese nula e a hipótese $\mathrm{H}_{2}$ será a hipótese alternativa, ou seja, a que se supõe inicialmente como verdadeira. A partir de testes realizados sobre as hipóteses $\mathrm{H}_{1}$ e $\mathrm{H}_{2}$ será verificado se existe influência do nível de governança corporativa sobre o valor de mercado das corporações com capital aberto listadas na BM\&FBOVESPA, no ano de 2012.

Para análise, foram utilizados o teste $t$ de Student e o teste $F$ de Fischer- Snedecor.

$\mathrm{O}$ teste $F$ de Fischer-Snedecor avalia a significância global de um modelo hipotético. Ele faz a análise da significância conjunta das variáveis explicativas em um modelo de regressão. Já o teste $t$ de Student verifica a significância das variáveis independentes que compõem um modelo de regressão. (FÁVERO et al., 2009).

Em relação aos resultados, esperou-se que, neste estudo, fosse apontada a influência da governança sobre o desempenho de mercado das empresas listadas na BM\&FBOVESPA no ano de 2012, convergindo com os resultados da pesquisa de Marques (2011). Tal

GєCont, v.2, n. 1, Floriano-PI, Jan-Jun. 2015. 
expectativa deveu-se ao fato de que o valor de mercado, expresso no valor das ações e na quantidade de títulos vendidos, sofre rapidamente as consequências da confiança que a empresa transmite, atentando-se à questão de que a credibilidade e a confiança são características relativas às organizações que possuem governança corporativa.

\subsection{Etapas da Pesquisa}

A pesquisa, de modo simplificado, foi realizada conforme as seguintes etapas e fases:

Estudo bibliográfico: nesta etapa foi realizada uma análise teórica acerca da governança corporativa, permitindo-se referenciar o presente trabalho e a metodologia utilizada.

Coleta de dados: os dados foram obtidos através da base Economática ${ }^{\circledR}$. Tais dados referiram-se ao valor de mercado e aos níveis de governança das empresas listadas na BM\&FBOVESPA, no ano de 2012.

Operacionalização do modelo: as variáveis foram trabalhadas através de regressões lineares simples, estabelecendo-se o relacionamento entre nível de governança e valor de mercado. Nesta etapa foi utilizado o software SPSS.

Transformações Box-Cox: como as variáveis dependentes não apresentaram, inicialmente, normalidade na distribuição de seus resíduos, gerando problemas de heteroscedasticidade, foram realizadas estas transformações, objetivando-se a obtenção da homoscedasticidade e normalidade na distribuição residual. Para esta etapa foi utilizado o software R.

Nova operacionalização do modelo com as variáveis transformadas: novamente são feitas as regressões lineares simples entre os níveis de governança e as variáveis transformadas.

Na próxima seção será realizada a análise de dados da presente pesquisa, mostrando-se os resultados dos testes de hipóteses e a análise da regressão entre governança e o desempenho de mercado.

\section{ANÁLISE DE RESULTADOS}

\subsection{Análise da Regressão Linear}

Inicialmente, foi feita uma regressão linear simples, considerando-se que os erros eram normalmente distribuídos, sendo o valor de mercado a variável dependente e o nível de governança corporativa a variável independente. Porém, a suposição de normalidade dos erros não foi satisfeita, conforme pode ser visto no Gráfico 1 dos resíduos, e no teste de JarqueBera, expresso na Tabela 4, ocorrendo problemas de heteroscedasticidade.

Gráfico 1 - Gráfico quantil-quantil da distribuição dos resíduos da regressão linear simples entre Níveis de GC e Valor de Mercado, das empresas da BM\&FBOVESPA, no ano de 2012. 


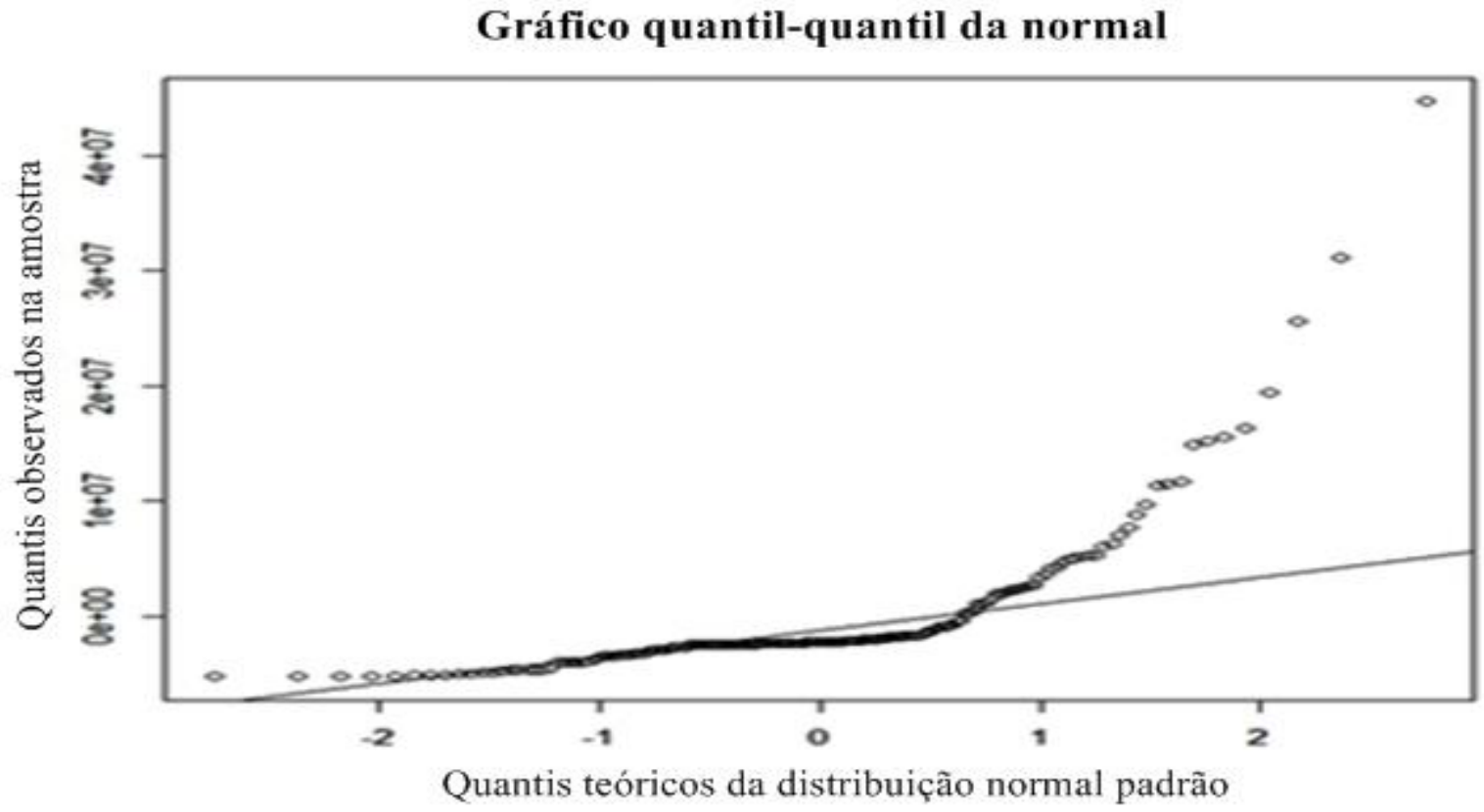

Fonte: Dados da pesquisa, 2014.

Tabela 4 - Resultados do Teste Jarque-Bera da regressão linear entre Níveis de GC e Valor de Mercado, das empresas da BM\&FBOVESPA, no ano de 2012.

\begin{tabular}{c|ccc}
\hline X-quadrado & Df & p-valor \\
\hline 2223,208 & 2 & 0,0000 \\
\hline
\end{tabular}

Fonte: Dados da pesquisa, 2014.

O teste Jarque-Bera apresentou p-valor igual a 0 (zero), o que significa que o modelo não apresentou erros normalmente distribuídos. Rejeitou-se, então, o modelo. Para solução do problema, foi utilizada a transformação Box-Cox na variável dependente (valor de mercado). A partir disso, a suposição de normalidade foi satisfeita.

O Gráfico 2, de log-verossimilhança, mostrado a seguir, aponta um $\lambda$ (lambda) muito próximo de 0 (zero), optando-se por lambda igual a zero para a transformação. 
Gráfico 2 - Gráfico de log-verossimilhança apresentando $\lambda$ para a conversão dos valores de mercados das empresas da BM\&FBOVESPA para o ano de 2012.

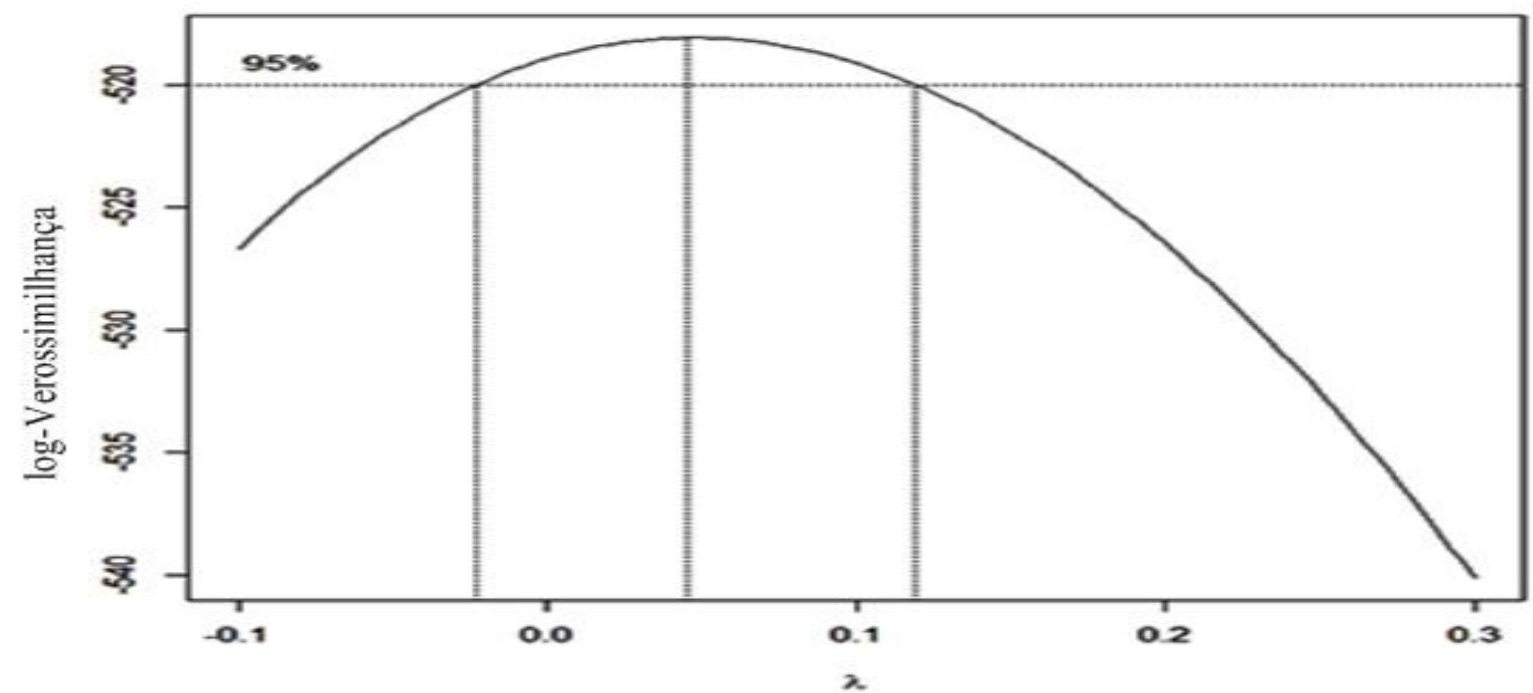

Fonte: Dados da pesquisa, 2014.

A partir de $\lambda$ (lambda) igual a zero, a metodologia Box-Cox aplicada sobre as variáveis dependentes segue a fórmula expressa na equação (3), onde se convertem os valores das variáveis em seus logaritmos naturais.

$$
T(y)=\ln y, \quad \text { se } \lambda=0 .
$$

O Gráfico 3 e a Tabela 5, a seguir, mostram os novos resultados.

Gráfico 3 - Gráfico quantil-quantil da distribuição dos resíduos da regressão linear simples entre Níveis de GC e logaritmo do valor de mercado, no ano de 2012.

\section{Gráfico quantil-quantil da normal}

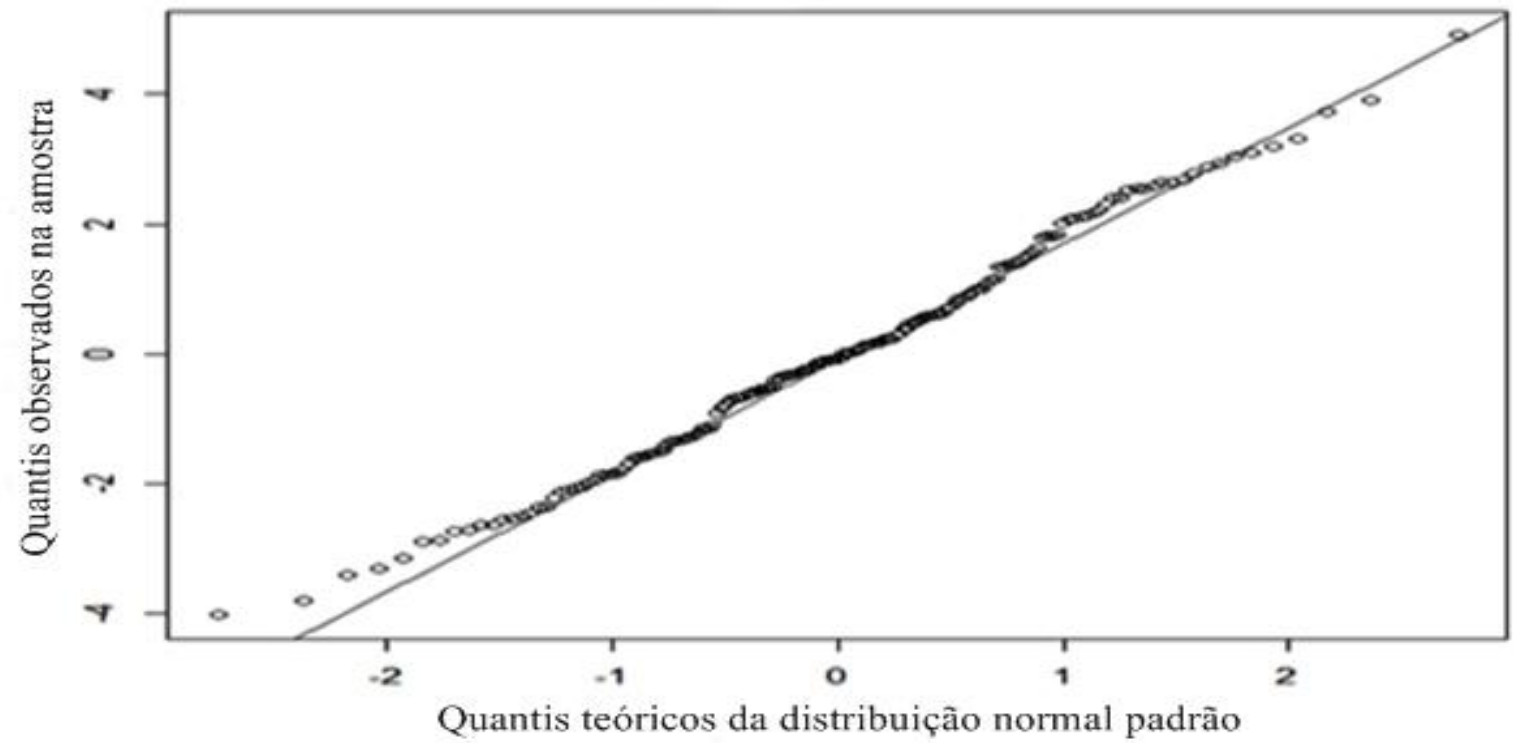

Fonte: Dados da pesquisa, 2014.

GєCont, v.2, n. 1, Floriano-PI, Jan-Jun. 2015. 
Tabela 5 - Resultados do Teste Jarque-Bera da regressão linear entre Níveis de GC e logaritmo do valor de mercado, no ano de 2012.

\begin{tabular}{c|c|c}
\hline X-quadrado & df & p-valor \\
\hline 1,5753 & 2 & 0,4549 \\
\hline
\end{tabular}

Fonte: Dados da pesquisa, 2014.

Ao se analisar o teste Jarque-Bera, verificou-se que os erros do novo modelo são normalmente distribuídos, pois o p-valor foi de 0,4549 , estando num nível muito bom, visto que os resíduos passam a ter distribuição normal, e os problemas de heteroscedasticidade são eliminados. Deste modo, toda a análise estatística é realizada sobre os valores convertidos.

O teste $F$ de Fischer-Snedecor, que testa globalmente o modelo, indicou que a relação entre nível de governança corporativa e $l n$ de valor de mercado é altamente significativa, havendo baixa probabilidade de erro. Este resultado está expresso na Tabela 6 .

Tabela 6 - Teste $F$ da regressão linear entre Níveis de GC e logaritmo do valor de mercado, no ano de 2012.

\begin{tabular}{ccccccc}
\hline \multicolumn{7}{c}{ ANOVA } \\
\hline \multicolumn{1}{c}{ Modelo } & $\begin{array}{c}\text { Soma dos } \\
\text { quadrados }\end{array}$ & df & Quadrado médio & $F$ & Sig. \\
& Regressão & 153,601 & 1 & 153,601 & 50,681 & 0,000 \\
1 & Residual & 500,073 & 165 & 3,031 & & \\
& Total & 653,674 & 166 & & &
\end{tabular}

a. Variável Dependente: $\ln \mathrm{VM}$

b. Preditoras: (Constante), Nível de GC

Fonte: Dados da pesquisa, 2014.

O teste $t$ de Student, da mesma forma, indicou que a variável independente do modelo, nível de governança corporativa, é altamente significativa, ao intervalo de confiança de $95 \%$. Estes resultados são mostrados na Tabela 7, a seguir.

Tabela 7 - Teste $t$ sobre as variáveis da regressão linear entre Níveis de GC e logaritmo do valor de mercado, no ano de 2012.

\begin{tabular}{|c|c|c|c|c|c|c|c|c|}
\hline \multicolumn{9}{|c|}{ Coeficientes } \\
\hline & \multirow[t]{2}{*}{ Modelo } & \multicolumn{2}{|c|}{$\begin{array}{c}\text { Coeficientes não } \\
\text { padronizados }\end{array}$} & \multirow{2}{*}{$\begin{array}{c}\text { Coeficientes } \\
\text { padronizados } \\
\text { Beta }\end{array}$} & \multirow[t]{2}{*}{$T$} & \multirow[t]{2}{*}{ Sig. } & \multicolumn{2}{|c|}{$\begin{array}{l}95 \% \text { de interv. } \\
\text { de conf. para B }\end{array}$} \\
\hline & & B & $\begin{array}{l}\text { Estat. de } \\
\text { Erro }\end{array}$ & & & & $\begin{array}{l}\text { Limite } \\
\text { inf. }\end{array}$ & $\begin{array}{l}\text { Limite } \\
\text { sup. }\end{array}$ \\
\hline 1 & Constante & 12,756 & 0,192 & & 66,52 & 0,000 & 12,377 & 13,134 \\
\hline & Nível GC & 0,690 & 0,097 & 0,485 & 7,12 & 0,000 & 0,499 & 0,882 \\
\hline
\end{tabular}

Fonte: Dados da pesquisa, 2014.

Assim, rejeita-se a hipótese nula $\mathrm{H}_{1}$ e se aceita a hipótese alternativa $\mathrm{H}_{2}$. Esta hipótese indica que o nível de governança corporativa influencia o valor de mercado das empresas listadas na BM\&FBOVESPA. Portanto, acredita-se que o valor de mercado das companhias 
listadas na BM\&FBOVESPA é determinado em grande parte pelo nível de governança corporativa das mesmas.

As práticas de governança corporativa, desta forma, devem ser adotadas pelas mesmas, a fim de melhorar seu desempenho financeiro, aumentando seu valor de mercado, o que é o objetivo dos acionistas e de vários stakeholders relacionados à organização.

Em relação à análise da regressão, foram encontrados os seguintes coeficientes de correlação R e de determinação $\mathrm{R}^{2}$, mostrados na Tabela 8.

Tabela 8 - Resumo do modelo da regressão linear entre Níveis de GC e logaritmo do valor de mercado, no ano de 2012.

\begin{tabular}{lcccc}
\hline \multicolumn{4}{c}{ Resumo do Modelo } \\
\hline Modelo & $\mathrm{R}$ & R-Quadrado & $\begin{array}{c}\text { R-Quadrado } \\
\text { Ajustado }\end{array}$ & Erro da Estimativa \\
1 & 0,485 & 0,235 & 0,230 & 1,740903036 \\
a. Preditoras: (Constante), Nível de GC & & \\
b. Variável Dependente: $\ln$ VM & \\
\hline
\end{tabular}

Fonte: Dados da pesquisa, 2014.

O modelo aponta a existência de relação entre as duas variáveis, com um coeficiente de correlação R de Pearson de 0,485 , ou seja, de 48,5\%. Este valor é considerado moderado positivo, significando que à medida que o nível de governança corporativa aumenta o logaritmo do valor de mercado das organizações da BM\&FBOVESPA também cresce.

O R $\mathrm{R}^{2}$ (R-quadrado) ou coeficiente de determinação foi de 23,5\%. Partindo-se do princípio de que um único fator (nível de Governança Corporativa) determina em 23,5\% o logaritmo do valor de mercado destas organizações, considera-se que este é um valor alto e satisfatório para o $\mathrm{R}^{2}$.

A regressão do modelo está expressa na equação (4) e mostra que quanto mais se aumenta o nível de governança corporativa nas companhias de capital aberto, mais se eleva o logaritmo natural do valor de mercado das mesmas.

$$
\ln V M=12,756+0,690 . \text { NivGov }
$$

Conforme esta equação, o coeficiente linear $\left(B_{0}\right)$ da regressão é 12,756 , e o coeficiente de angulação $\left(\mathrm{B}_{0}\right)$ é 0,690 . Isto significa que, ceteris paribus, quando o nível de governança corporativa é zero, o logaritmo do valor de mercado é 12,756, e que a cada aumento de uma unidade no nível de governança corporativa, o logaritmo do valor de mercado aumenta em 0,69. Em relação à equação (4), salienta-se, ainda que, para se obter o valor de mercado da corporação, é necessário $\mathrm{e}^{\text {(y estimado) }}$, dado que o modelo está sendo trabalhado com o logaritmo dos valores de mercado.

A reta de regressão linear correlacionando o nível de governança corporativa com o logaritmo do valor de mercado das empresas está plotada no Gráfico 4. Importante notar que a mesma é ascendente, o que confirma a análise realizada. 
Gráfico 4 - Gráfico de dispersão entre nível de governança corporativa e logaritmos dos valores de mercado, no ano de 2012.

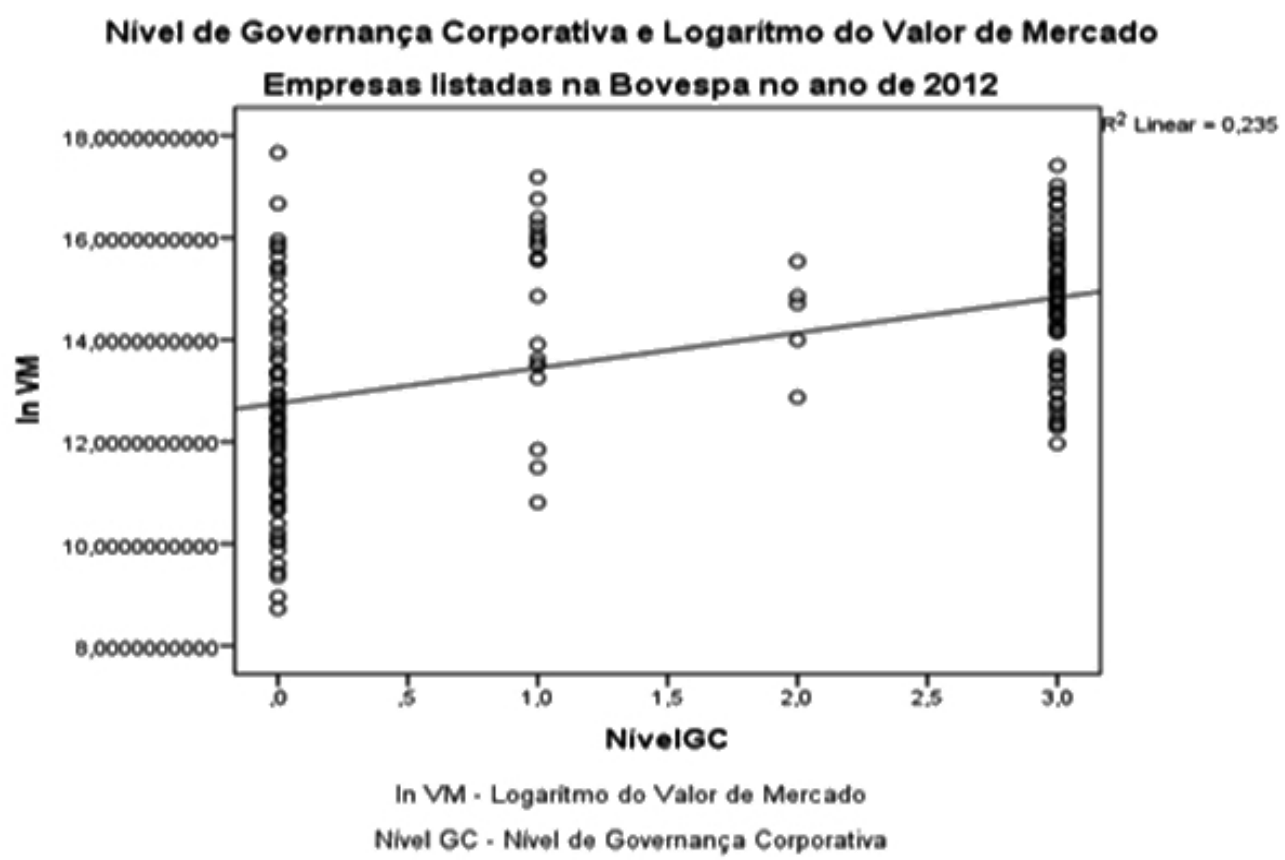

Fonte: Dados da pesquisa, 2014.

Percebe-se, desta forma, que o valor de mercado das organizações em análise é definido em grande parte pela governança corporativa. Quanto mais as organizações passam a adotar as boas práticas de governança, maiores as probabilidades de aumento no seu valor de mercado, o que pode proporcionar maiores retornos para todas as partes interessadas (stakeholders) de tais empresas.

\section{CONSIDERAÇÕES FINAIS}

A governança corporativa é um mecanismo que tem passado por vários estudos, com a finalidade de se saber se a mesma contribui com o desempenho ou com a valorização de organizações. Várias análises já foram feitas, mas um resultado definitivo ainda não foi encontrado. Neste sentido, este trabalho verificou as relações entre governança e o indicador da performance de mercado das empresas listadas na BM\&FBOVESPA. Foram supostas 2 (duas) hipóteses, $\mathrm{H}_{1}$ e $\mathrm{H}_{2}$, referentes ao relacionamento entre os níveis de governança corporativa da BM\&FBOVESPA e o valor de mercado das empresas listadas.

Para a análise dessas relações foram feitas regressões lineares simples entre nível de governança e valor de mercado. Com os dados brutos das variáveis dependentes, entretanto, os modelos não atenderam à suposição de normalidade na distribuição dos resíduos, o que propôs que os mesmos apresentaram problemas de heteroscedasticidade.

Para resolução do problema de normalidade na distribuição dos resíduos, as variáveis dependentes (valor de mercado) foram transformadas por Box-Cox e Yeo-Johnson. Com as transformações efetuadas, a regressão estimada apresentou resíduos normalmente distribuídos, atendendo ao pressuposto de homoscedasticidade e normalidade dos resíduos, além de gerar resultados significantes.

Assim, confirmaram-se os resultados esperados da pesquisa, em que se acreditava que 
a governança influencia o desempenho de mercado, sendo determinante para a valorização de mercado da organização, dada a maior confiança gerada pelo público.

Verificou-se ainda que, no ano de 2012, para as empresas que não possuíam nenhum nível de governança corporativa, o logaritmo do valor de mercado foi de 12,756 , e que a cada unidade do nível de governança que aumentou, houve um aumento de 0,690 no logaritmo do valor de mercado. Estes modelos apresentaram alta significância tanto no teste $t$ quanto no teste $F$, aos níveis de $95 \%$.

Isto faz com que se perceba que a organização bem gerenciada dentro dos padrões de governança, utilizando-se da transparência e da ética, e do tratamento equitativo e igualitário de seus shareholders e stakeholders, tende a ser mais valorizada. No momento do investimento, os acionistas levam em consideração o atendimento a estas demandas sociais e legais para efetuarem a aplicação de capital em tais empresas.

A pesquisa não apresenta resultados definitivos sobre a problemática trabalhada, porém, diante de tais resultados, propõe-se às empresas que invistam a cada dia mais nas boas práticas de governança corporativa, dado que isto faz com que se aumente a credibilidade da organização frente ao mercado, bem como a valorização da mesma. Incentiva-se, também, os investidores a estarem a cada dia mais atentos às práticas de governança das empresas em que alocam seus capitais, já que existe uma tendência de maior valorização das mesmas quando elas adotam compromissos éticos com seu mercado de acionistas, por meio da governança.

Sugere-se, ainda, que os órgãos reguladores incentivem cada dia mais as práticas de governança corporativa, com vistas a desenvolver o mercado de capitais do país. Acrescentase, também, a importância das instituições de ensino frente a este cenário. Enquanto formadoras e aperfeiçoadoras de profissionais e de gestores, espera-se que haja continuamente o incentivo educacional às ações morais e éticas, ressaltando-se a importância do ensino de disciplinas portadoras deste enfoque nos cursos de Administração, Contabilidade e Economia.

A pesquisa possui como limitação a exclusão dos outliers (valores anormais), que provoca certa alteração nos resultados gerais obtidos. Há, também, a propensão à presença da causalidade reversa. Do mesmo modo em que se percebe o nível de governança como influenciador do desempenho da empresa, pode existir a relação contrária, em que o desempenho influencia o nível de governança. Tal problema pode ser alvo de investigações futuras.

Outra limitação, ainda, se refere ao uso de regressões lineares simples (dado que os modelos múltiplos testados não se mostraram significativos), pois este método omite outras variáveis que podem ser importantes para o desempenho da empresa.

Sugere-se que outros estudos sejam feitos na área, buscando-se utilizar de modelos de regressões múltiplas, em que outros fatores explicativos (referentes à governança) sejam utilizados como variáveis endógenas. Assim, pode-se verificar como reage o desempenho das organizações a cada um dos fatores isoladamente ou em conjunto.

\section{REFERÊNCIAS}

ALVES, L. E. S. Governança e cidadania empresarial. Revista de Administração de Empresas - Fundação Getúlio Vargas, São Paulo, v.41, n. 4, p. 78-86, out./dez. 2001. Disponível em: <http://www.scielo.br/pdf/rae/v41n4/v41n4a09.pdf>. Acesso em: 11 abr. 2013. 
ANDRADE, G. A. R. Estudo econométrico dos efeitos da migração para o IGC: índice de ações com governança corporativa Diferenciada da Bovespa. Revista Eletrônica de Negócios Internacionais - Escola Superior de Propaganda e Marketing, São Paulo, v. 3, n. 1, p.39-53, jan./jun. 2008. Disponível em:

<http://internext.espm.br/index.php/internext/article/view/64>. Acesso em: 24 set. 2013.

BARNEY, J. B.; HESTERLY, W. S. Administração estratégica e vantagem competitiva. Tradução de Monica Rosemberg. São Paulo: Pearson Prentice Hall, 2007.

CAMILO. S. P. O.; MARCON, R.; BANDEIRA-DE-MELLO, R. Conexões Políticas e desempenho das empresas listadas na BM\&FBOVESPA: Análise sob a ótica da governança e da dependência de recursos. In: ENCONTRO DA ANPAD, 35., 2011, Rio de Janeiro.

Anais eletrônicos... Rio de Janeiro, 2011. Disponível em:

$<$ http://www.anpad.org.br/evento.php?acao=trabalho\&cod_edicao_subsecao=736\&cod_event o_edicao=58\&cod_edicao_trabalho=13111>. Acesso em: 22 mar. 2013.

COLOMBO, J. A.; GALLI, O. C. Governança corporativa no Brasil: níveis de governança e rendimentos anormais. Revista Portuguesa e Brasileira de Gestão - Fundação Getúlio Vargas, Lisboa, v.9, n. 4, p. 26-37, out./dez. 2010. Disponível em: $<$ http://www.scielo.gpeari.mctes.pt/scielo.php?script=sci_pdf\&pid=S1645$44642010000300004 \& \operatorname{lng}=$ pt\&nrm=iso\&tlng=pt>. Acesso em: 17 mar. 2013.

COVA, C. J. G.; SANTOS, R. G. A governança corporativa e a geração de valor nas empresas do mercado de capitais. In: SIMPÓSIO DE EXCELÊNCIA EM GESTÃO E TECNOLOGIA, 4., 2007, Rio de Janeiro. Anais eletrônicos... Rio de Janeiro, 2007. Disponível em:

<http://www.aedb.br/seget/artigos07/817_Governanca\%20Corporativa\%20e\%20a\%20geraca o\%20de $\% 20$ valor $\% 20$ nas $\% 20$ empresas $\% 20 \mathrm{do} \% 20$ Mercado $\% 20 \mathrm{de} \% 20$ capitais.pdf $>$. Acesso em: 23 jul. 2013.

DOMENEGHETTI, D.; MEIR, R. Ativos Intangíveis: como sair do deserto competitivo dos mercados e encontrar um oásis de valor e resultados para sua empresa. Rio de Janeiro: Elsevier, 2009.

ECONOMÁTICA. Indicadores de mercado. 2012. Disponível em: $<\mathrm{http}$ //www.economatica.com/support/manual/portugues/Indicadores/Indicadores_de_merca do.htm>. Acesso em: 05 fev. 2014.

FÁVERO, L. P.; CHAN, B. L.; SILVA, F. L.; BELFIORE, P.P. Análise de Dados: modelagem multivariada para tomada de decisões. Rio de Janeiro: Elsevier, 2009.

FERREIRA, R. N. Responsabilidade Social, governança corporativa e valor das empresas. Revista de Administração da UFLA - Universidade Federal de Lavras, Lavras, v.6, n.1, p. 132-142, jan./jun. 2004. Disponível em: <http://revista.dae.ufla.br/index.php/ora/article/view/235>. Acesso em: 23 jul. 2013.

GABRIEL, F.; SILVEIRA, A. M. O Impacto da adesão às práticas recomendadas de governança corporativa no índice de qualidade da informação contábil das firmas no Brasil. Prêmio IBGC Itaú Academia e Imprensa. São Paulo, 2011. Disponível em: $<$ http://www.ibgc.org.br/Download.aspx?Ref=Arquivos\&CodArquivo=685>. Acesso em: 02 ago. 2013.

GALDI, F. C.; TEIXEIRA, A. J. C.; LOPES, A. B. Análise empírica de modelos de valuation no ambiente brasileiro: fluxo de caixa descontado versus modelo de Ohlson (RIV). Revista Contabilidade \& Finanças - Universidade de São Paulo, São Paulo, v. 19, n. 47, p. 
31-43, maio/ago. 2008. Disponível em:

<http://www.scielo.br/pdf/rcf/v19n47/v19n47a04.pdf>. Acesso em: 18 mar. 2014.

GITMAN, L. J. Princípios de Administração Financeira. Tradução de Jorge Ritter. 2. ed. Porto Alegre: Bookman, 2001.

IBGC. Código das Melhores Práticas de Governança Corporativa. 4. Ed. São Paulo: IBGC, 2009. Disponível em: <http://www.ibgc.org.br/userfiles/files/Codigo_Final_4a_Edicao.pdf>. Acesso em: 16 mar. 2013.

MARINELLI, M. Um estudo exploratório sobre o estágio da Governança Corporativa nas Empresas Brasileiras. Revista Brasileira de Gestão de Negócios - Fundação Escola de Comércio Álvares Penteado, São Paulo, v. 7, n. 19, p.57-66, set./dez. 2005. Disponível em: <http://rbgn.fecap.br/RBGN/article/view/50/43>. Acesso em: 22 mar. 2013.

MARQUES, S. S. Impacto de práticas de Governança Corporativa de empresas brasileiras de capital aberto sobre seu desempenho e avaliação de mercado. Prêmio IBGC Itaú Academia e Imprensa. São Paulo, 2011. Disponível em: <http://www.ibgc.org.br/Download.aspx?Ref=Arquivos\&CodArquivo=686>. Acesso em: 02 ago. 2013.

MARTINS, G. S.; BRITO, L. A. L.; TESCARI, F. V. C. S. A medida de confiar é confiar sem medida? Estudo sobre o efeito da confiança na criação e na captura de valor na relação comprador-fornecedor. In: ENCONTRO DA ANPAD, 37., 2013, Rio de Janeiro. Anais eletrônicos... Rio de Janeiro, 2013. Disponível em:

$<$ http://www.anpad.org.br/evento.php?acao=trabalho\&cod_edicao_subsecao=966\&cod_event o_edicao=68\&cod_edicao_trabalho=16076>. Acesso em: 01 out. 2013.

MELO, R. S.; BATISTA, P. C. S.; MACEDO, A. C. M.; COSTA, R. B. L. A contribuição da governança corporativa para o desempenho das empresas brasileiras de capital aberto. Revista de Gestão - Universidade São Paulo, São Paulo, v. 20, n. 1, p.79-92, jan./mar. 2013. Disponível em: <http://www.regeusp.com.br/arquivos/1443.pdf>. Acesso em: 24 jul. 2013.

ROGERS, P.; SECURATO, J. R.; RIBEIRO, K. C. S. Governança corporativa, custo de capital e retorno do investimento no Brasil. Revista de Gestão - Universidade de São Paulo, São Paulo, v. 15, n. 1, p. 61-77, jan./mar. 2008. Disponível em: Acesso em: <http://www.regeusp.com.br/arquivos/509.pdf>. Acesso em: 23 jul. 2013.

ROSS, S. A.; WESTERFIELD, R. W.; JORDAN; B. D. Administração Financeira. Tradução de Antônio Zoratto Sanvicente. 2. ed. São Paulo: Atlas, 2002.

ROSSETTI, J. P., ANDRADE, A. Governança Corporativa: fundamentos, desenvolvimento e tendências. 6. ed. São Paulo: Atlas, 2012.

ROSSONI, L.; MACHADO-DA-SILVA, C. L. Legitimidade, governança corporativa e desempenho: análise das empresas da BM\&FBOVESPA. Revista de Administração de Empresas - Fundação Getúlio Vargas, São Paulo, v. 53, n. 3, p. 272-289, maio/jun. 2013. Disponível em: <http://rae.fgv.br/sites/rae.fgv.br/files/artigos/10.1590-00347590201300300005.pdf >. Acesso em: 01 out. 2013.

SAITO, R.; SILVEIRA, A. M. Governança Corporativa: Custos de Agência e Estrutura de Propriedade. Revista de Administração de Empresas - Fundação Getúlio Vargas, São Paulo, v. 48, n. 2, p. 79-86, abr./jun. 2008. Disponível em: <http://www.scielo.br/pdf/rae/v48n2/v48n2a07.pdf>. Acesso em: 16 abr. 2013.

GєCont, v.2, n. 1, Floriano-PI, Jan-Jun. 2015. 
SILVEIRA, A. M. Governança corporativa no Brasil e no mundo: teoria e prática. Rio de Janeiro: Elsevier, 2010.

SILVEIRA, A. M.; BARROS L. A. B. C.; FAMÁ, R. Atributos corporativos, qualidade da governança corporativa e valor das companhias abertas no Brasil. Revista Brasileira de Finanças - Sociedade Brasileira de Finanças, Rio de Janeiro, v. 4, n. 1, p. 1-30, 2006. Disponível em:

<http://bibliotecadigital.fgv.br/ojs/index.php/rbfin/article/viewFile/1153/244>. Acesso em: 01 out. 2013.

Determinantes do nível de governança corporativa das companhias abertas brasileiras. In: SEMINÁRIOS EM ADMINISTRAÇÃO FEA-USP, 7., 2004, São Paulo. Anais eletrônicos... São Paulo, 2004. Disponível em: <http://www.ead.fea.usp.br/Semead/7semead/paginas/artigos\%20recebidos/Finan\%E7as/FIN 19_-_Determinantes_do_nivel_governan\%E7a.PDF>. Acesso em: 23 jul. 2013.

Estrutura de Governança e desempenho financeiro nas companhias abertas brasileiras: um estudo empírico. Caderno de Pesquisas em Administração - Programa de pós-graduação em Administração da FEA-UFP, São Paulo, v. 10, n.1, p.57-71, jan./mar. 2003. Disponível em: <http://www.ead.fea.usp.br/cad-pesq/arquivos/v10n1art5.pdf>. Acesso em: 24 jul. 2013.

SOUZA, G. N.; CARNEIRO, A. P. S.; CECON, P. R.; SANTOS, G. R.; MALHADO, C. H. M. Transformação aritmética e de ordem para análise de dados com heterogeneidade de variâncias. In: REUNIÃO ANUAL DA RBRAS, 57., 2012. Piracicaba. Resumo. Piracicaba: USP, 2012. Disponível em:

$<$ http://www.rbras.org.br/rbras57/sites/default/files/submissoes/RESUMO\%20ESTENDIDO_ 1.pdf>. Acesso em: 15 fev. 2014

WOOLDRIDGE, J. M. Introdução à Econometria: uma abordagem moderna. Tradução de Rogério Cézar de Souza, José Antônio Ferreira. São Paulo: Thomson Learning, 2007. 